\title{
Quality of Life and Sexual Risk Behaviour among Adolescent
}

\author{
Gisely Vionalita
}

\author{
Department of Public Health, Faculty of Health Sciences, Universitas Esa Unggul, Indonesia
}

\begin{abstract}
Recent national data on North Sumatera Province suggest that within last two years, 22\% of woman were married before they are 16 years old, and most of them were cause by unplanned pregnancy. Adolescence is widely considered as critical periods in human development, in which, being effected by how the environment change their quality of life (QoL). Perceived QoL in adolescents can be useful in recognizing of adolescents in health-risk behavior. The objective of the study is to obtain relationship between sexual risk behavior and quality of life among adolescent in junior high school in North Sumatera, Indonesia. The PEDSQL Questionnaire (ages 8-12) and sexual risk behavior questionnaire were applied to 166 junior high school students. It is found that in there is significant relationship between sexual risk behavior and quality of life $(\mathrm{P}<0.05)$. Thus, improving the knowledge about health-related behaviors and perceived QoL in adolescence, especially included in the school curriculum is definitely important to promote health behavior as a foundation for health and quality of life in the future.
\end{abstract}

Keywords: quality of life, sexual risk, adolescent, PEDSQL Questionnaire

\section{Introduction}

Until 2015, the total population of adolescent worldwide reaches 1.2 billion people. Based on data released by the Central Bureau of Statistics (BPS), the number of adolescents reaches more than 63 million or 26.6\% percent of 237.6 million population of Indonesia. North Sumatra itself has 1.3 million adolescent from 13.53 million of people or $9.6 \%$ (BPS, 2014).

Adolescence is one of the most important national assets in preparing future generations. In addition, the adolescent population occupies a significant number in Indonesia. Every action made teenagers are now in the spotlight because the problems of teenagers so complex, not only about physical development but also psychosocial. The developments that occur today either the condition of technology, science knowledge as well as social and cultural conditions can lead to pressures in adolescence that caused behavioral disorders in adolescents (Achjar, 2006).

Perceived QoL in adolescents can be useful in identifying subgroups of children and adolescents at risk of engaging in health-compromising behaviors and it can also assists in determining the burden of a particular disease or disability. In fact, adolescence is a vulnerable period in human development characterized by numerous bio-psycho-social changes that may influence the engagement in health-related risk behaviors. For instance, results in thirty nine countries and regions across Europe and North America from the Health Behaviour in School-Aged Children (HBSC) study, conducted in 2010 with adolescents aged 11 to 18th, found that, there was possibility of the adolescents reported a good health status, however they might be experienced unhealthy lifestyles or enhanced risk behaviours.

Based on WHO data in 2015, the main problem among adolescents globally is the death of girls aged 15 to 19 years caused by complications during pregnancy and birth. An estimated $11 \%$ of births worldwide occur in girls aged 15-19 years, and the largest are in third world countries. According to UN Population Division data, worldwide estimated 44 of 1000 births are young girls who are still under age. Every year, estimated 3 million young women ages 15-19 years have unhealthy abortions. Since 2011 until now known that 140 million girls in 
the world have been married at the age of less than 18 years and 50 million married in the age of less than 15 years. While at this age, the female reproductive organs are still in the process of development that causes young women are vulnerable to health problems in reproductive organs. In addition, the impact of unhealthy sexual behavior can increase the occurrence of increased transmission of HIV which is one cause of high mortality in adolescents. Consumption of alcohol and narcotics can also lead to unsafe sex behavior (WHO, 2015).

According to data released by the Ministry of Health of the Republic of Indonesia on Adolescent Reproductive Health Situation, it is found that $4.5 \%$ of male teenagers have premarital sexual intercourse between the ages of $15-19$ and $14.6 \%$ at age $20-24$ years. While $0.7 \%$ of teenage girls had premarital sexual intercourse at the age of (15-19) years and $1.8 \%$ at the age of (20-24) years. From the breakdown the data teenage girl engaged with sexual risk behaviour above, it is also known that only $40.5 \%$ of $15-19$ year old girls use condoms during sex and only $61 \%$ of teenagers who have sex with only 1 partner. It is of course prone to be the cause of early pregnancy and early childbirth, early marriage, abortion, HIV infection and contracting sexually transmitted diseases. In addition, according to data from the United Nations Development Economic and Social Affairs (UNDESA) in 2010, Indonesia entered into 37 countries with the highest number of young marriages.

Based on the population census conducted by Central Bureau of Statistics in North of Sumatera mentioned that 10 to $11 \%$ of women of reproductive age (WUS) were married at the age of 16 years in 2010, and according to BPS North Sumatra itself at least $47.79 \%$ of women in rural areas married under the age of 16, while in urban reached 21.75\% in 2011. One of the specific targets of the Sustainable Development Goal (SDG) health sector in 2030, that the world has ensured access to sexual and reproductive health services, this service includes family planning, information and education and health strategies and programs integrated national reproduction. According to WHO, many factors affect teenagers' sexual behavior, such as adolescent's own knowledge about sex and its impact on the health of reproductive organs. In addition, there are still many countries that assume that sex is something that unable to discuss explicitly in the family and school environment, technological advances and internet access easier so that many teenagers who get information quickly but not accurately accompanied by changes style of intercourse in the teenagers environment where premarital sexual activity becomes a trend of its own that is difficult to be prevented and the role of parents who are considered minimal in assisting teenagers during the growth (WHO, 2015).

Premarital sex behavior that is at risk of course affects adolescent reproductive health. In addition, adolescents are golden periods that should be filled with positive activities. The attitude of a teenager is of course influenced by knowledge and the environment. From the three researches described above, it can be concluded that the factors affecting reproduction health ranging from the characteristics of adolescents themselves such as age, gender, knowledge followed by the environment such as family, school, social interaction and technological advances that make it easier for teenagers to be exposed to information which if not get the right guidance will cause the entry of wrong information which then trigger the tendency of wrong behavior as well.

Public Junior High School 2 in Perbaungan, is a junior high school located in Serdang Bedagai District in North Sumatera Province. Based on existing records, this incident is experienced 1 (one) student in 2015 and 1 (one) student in 2016. The aim of the present study was to examine sexual risk behavior and cross-cultural differences in adolescent perceived QoL from school in North Sumatera, Indonesia. This study aimed at contributing to the identification of sexual risk behavior that happens in adolescents and in regards to see the effect to their health and well-being, in order to inform and to improve health prevention policies and practice in the future studies.

\section{Methods}

An observational, study was carried out with 166 adolescents of Junior High School 2 Perbaung, North Sumatera between 15 and 17 years old. We have used two instruments in order to evaluate both QoL and sexual risk behaviors in adolescents, previously validated for Indonesian language. Quality of life: the PedsQoL child 
selfreport was used. This measure is aimed for the evaluation of perceived QoL in children and adolescents, aged between 13-18 years old. It consists of 23 items using likert scale 1 to 4-always to never, higher score indicate better score of quality of life. There were four multidimensional dimension, physical (8 items), Social (5 items), School function (5 items) and emotional function (5 items). Physical Well-Being (e.g., "Have you felt fit and well"), Social functioning (e.g., "Do you have problem to get along with your friends?"), Parent School function (e.g., "Do you have problem with school work?"), Emotional function (e.g., "Do you feel worried?"). Sexual risk behavior was reportedly using a stage of activity in terms of the stage of sexual risk activity that engaged by the adolescents (for instance, in the sexual behavior scale: "have you done your first sexual intercourse?"). This questionnaire originated in English that needed to be forward translated to Indonesian language and back translated to English. The questionnaire in Indonesia language then validated. Sociodemographic variables: the following data was collected - Adolescent's age and gender and mother's and father's academic qualifications.

The dependent variable of research is adolescent sexual behavior. The research instrument used was a questionnaire consisting of 1 question about risky actions carried out by respondents regarding sexual activity carried out against the opposite sex includes holding hands, stroking, hugging, embracing, kissing the cheeks, kissing the mouth, feeling sensitive areas, attaching genitals with or without clothes, oral sex to sexual intercourse. Assessment is done by giving a score of 1 , if the respondent is ever and 0 if never for holding hands until kissing the cheek while kissing the mouth until having sexual intercourse is given a score of 2 if ever and 0 if never. The results of the respondents' answers will be accumulated and categorized into 2 groups, namely low risk behavior and risky behavior.

The questionnaire was given in the school system and was answered by the adolescent themselves to avoid some leaking of information and to maintain the confidentiality. Analysis data were done using SPSS 17.0 and using chi square test. The data were categorized using median as cut off before applied to chi square test. This study was approved by the ethical Committee of Universitas Esa Unggul and all participant adolescents and their parents signed informed consents voluntarily.

\section{Results}

The average scores of the subscales in quality of life assessments from adolescents' perspective were showed that social functioning became the lowest score of quality of life. Nevertheless physical functioning become the highest score among that subscales. Data showed that 95(57.2\%) of adolescents as respondents were categorized in low quality of life using the median as a cut off.

Table 1 Table of frequency of adolescents' quality of life

\begin{tabular}{lll}
\hline Quality of Life & Frequency & Percentage \\
\hline Physical functioning & 1877 & $34 \%$ \\
\hline Emotional functioning & 1246 & $22 \%$ \\
\hline Social functioning & 1095 & $20 \%$ \\
\hline School functioning & 1344 & $24 \%$ \\
\hline Total & 5562 & $100 \%$ \\
\hline
\end{tabular}


Table 2

Table of category adolescents' quality of life

\begin{tabular}{lll}
\hline \multicolumn{1}{c}{ Quality of Life } & Frequency & Percentage \\
\hline High quality of life & 71 & $42.8 \%$ \\
\hline Low quality of life & 95 & $57.2 \%$ \\
\hline Total & 166 & $100 \%$ \\
\hline
\end{tabular}

For the sexual risk behavior, the data showed that only $50(30.1 \%)$ adolescents that particularly engage with no sexual activity. Meaning that, the rest of the respondents were actually engaged with the different stages of sexual activity behavior. It was found that most of the adolescents though in junior high school have some desire to try a sexual activity even still in the first stage. Additionally, the data showed that $116(69.9 \%)$ of the respondents were categorized as risk behaviours.

Table 3

Table of category adolescents' quality of life

\begin{tabular}{|c|c|c|}
\hline Sexual activity & Frequency & Percentage \\
\hline Holding hands & 50 & $32,5 \%$ \\
\hline Holding Hand, Rubbing and Hugging & 18 & $10,8 \%$ \\
\hline Holding Hand and Kiss on the Cheek & 26 & $15,6 \%$ \\
\hline Holding Hand and Touching sensitive Area & 1 & $0,6 \%$ \\
\hline Holding Hand, Hugging and Intercourse & 1 & $0,6 \%$ \\
\hline Holding Hand, Hugging and Oral Sex & 1 & $0,6 \%$ \\
\hline $\begin{array}{l}\text { Holding Hand, Hugging, Kiss on the Cheek and Oral } \\
\text { Sex }\end{array}$ & 1 & $0,6 \%$ \\
\hline $\begin{array}{l}\text { Holding Hand, Hugging, Kiss On the Cheek and } \\
\text { touching sensitive area }\end{array}$ & 2 & $1,2 \%$ \\
\hline Holding Hand and French Kiss & 6 & $3,6 \%$ \\
\hline $\begin{array}{l}\text { Holding Hand, Hugging, Kiss on the Cheek and } \\
\text { Touching sensitive Area }\end{array}$ & 1 & $0,6 \%$ \\
\hline $\begin{array}{l}\text { Holding Hand, Hugging, Kiss on the Cheek, French } \\
\text { Kiss and petting without clothes }\end{array}$ & 1 & $0,6 \%$ \\
\hline $\begin{array}{l}\text { Holding Hand, hugging, Kiss on the cheek, French kiss } \\
\text { and touching sensitive area }\end{array}$ & 1 & $0,6 \%$ \\
\hline $\begin{array}{l}\text { Holding Hand, hugging, Kiss on the cheek, French kiss, } \\
\text { touching sensitive area and petting with clothes }\end{array}$ & 1 & $0,6 \%$ \\
\hline $\begin{array}{l}\text { Holding Hand, hugging, Kiss on the cheek, French kiss, } \\
\text { necking, touching sensitive area and petting with } \\
\text { clothes }\end{array}$ & 1 & $0,6 \%$ \\
\hline $\begin{array}{l}\text { Holding Hand, hugging, Kiss on the cheek, French kiss, } \\
\text { necking, touching sensitive area, petting with clothes } \\
\text { and intercourse }\end{array}$ & 1 & $0,6 \%$ \\
\hline No sexual activity & 50 & $30,1 \%$ \\
\hline Total & 166 & $100 \%$ \\
\hline
\end{tabular}


Table 4

Table of category adolescents' sexual risk behaviours

\begin{tabular}{lll}
\hline \multicolumn{1}{c}{ Sexual Risk behaviours } & Frequency & Percentage \\
\hline Risk behaviours & 116 & $69.9 \%$ \\
\hline Unrisk behaviours & 50 & $30.1 \%$ \\
\hline Total & 166 & $100 \%$ \\
\hline
\end{tabular}

Bivariate analysis using chi square showed a significant linear positive relationship $(\mathrm{P}<0.005)$ between sexual risk behavior and quality of life. One single improvement in sexual risk behaviour increased the health status that indicated using quality of life with OR 4.473

Table 5 Table of chi-square test between sexual Risk Behaviour and quality of life

\begin{tabular}{|c|c|c|c|c|c|c|c|c|}
\hline \multirow{3}{*}{$\begin{array}{l}\text { Sexual Risk } \\
\text { Behaviour }\end{array}$} & \multicolumn{4}{|c|}{ Quality of Life } & \multicolumn{2}{|c|}{ Total } & \multirow{3}{*}{ P Value } & \\
\hline & \multicolumn{2}{|c|}{ Low QoL } & \multicolumn{4}{|c|}{ High QoL } & & \multirow[t]{2}{*}{ OR $95 \% \mathrm{CI}$} \\
\hline & $\mathrm{N}$ & $\%$ & $\mathrm{~N}$ & $\%$ & $\mathrm{~N}$ & $\%$ & & \\
\hline Risk & 50 & $60.20 \%$ & 33 & $39.80 \%$ & 83 & $100 \%$ & \multirow{2}{*}{0,000} & 4.473 \\
\hline Unrisk & 21 & $25.30 \%$ & 62 & $74.70 \%$ & 83 & $100 \%$ & & $\begin{array}{l}(2.381- \\
8.671)\end{array}$ \\
\hline
\end{tabular}

\section{Discussions}

This study has translated and validated the PedsQL questionnaire in Bahasa Indonesia and it can now be used in populations who understand Bahasa Indonesia within the Indonesian community especially for adolescent. The objective of this study was to obtain the relationship between sexual risk behavior and quality of life. As mentioned earlier, the score of adolescents' quality of life in this school have the lowest on in social functioning. Usually period human in this age have some unique characteristic. In this phase they will usually decide and influence their desire and passionate and how to achieve it. Peers relationship will become one of the factors to decide it. Hence, the successful of the people were effected with how they were spending their adolescents' life. In order to have a good quality in the future generations, it is necessary to have some program to concern with subscales in quality of life. All of these subscales in quality of life are closely related to perceptions of negativity and can thus be linked to perceptions of the ability in catch up with school-work and the frequency negative feelings in children, both of which have been shown in this study to be the main factors affecting the QoL and at the same time is able to influence the academic achievement. Additionally, for the sexual risk behavior it was found that $69.8 \%$ of adolescents were engaged with the sexual activity with different stages. Junior high school is actually still in the stage of early adolescents. This phase is the transitory between the primary school and the high school. Thus it is surprisingly, to see that in this stage were found adolescent have engaged with sexual activity in intercourse stage. Sexual risk behavior in adolescent is formed because of the closeness to the opposite sex. It suggests that the relationship with the opposite sex will cause feelings of security and comfort in adolescents. (Furnan \& Shaver, 2003). Thus the emotional need of the adolescents must be considered as important things that should covered from their parents and family. It is suggested that parents and family should considering to be the closest person that can be connected emotionally and physically that will not force the adolescents to find new source from other people.

From the statistical analysis mentioned before that there is significant relationship between sexual risk behavior and quality of life, meaning that we can achieve a good health status with a good sexual risk behavior. Sexuality is a natural process that will be felt by every individual who has experienced maturity in the reproductive organs. This is along with the maturation of sexual organs accompanied by physiological and hormonal changes, the adolescent will begin to explore sexuality in his life (Santrock, 2007). Therefore, adolescence needs to have the right education about sexuality, and prevent them to have sexual behavior at risk. Health education is 
somehow called 'taboo' in Indonesia, however, if we are still covering this issue it will become an iceberg problem. It is currently become clear that the ignorance of this issue could be the biggest mistake for quality of life. Thus as parents, we should know how and when to teach them about sexual activity. It starts from the early child by introducing them male and female word of terminology, usually it can open that conversation that commonly awkward to be discussed at home. It should start from the parents, school and the peers not in other way around.

Furthermore, this issue also needs specific approach from the school. In order to have a good behaviour, adolescents need to get a proper education about sexuality and begin to learn to be responsible for maintaining health and reproductive health from school. Proper means that not only talking about the organ and the functions but talking regarding the issue with human problem. Proper and comprehensive education should always be done from school, including the curriculum to form positive and risky adolescent sexual behavior (Kirby et al, 2007). Find a way to replace the negative thought to positive activity such as extracurricular activity. Adolescent knowledge of sexuality needs to be improved that family and school can do by providing comprehensive information about sexuality especially on infectious sexually transmitted infections so that adolescents can understand the effects and effects of risky sexual behavior both in the short and long term (Bearinger et al, 2007). Schools can also work with local health workers in providing sexuality and continuing education programs. In addition, to improve the positive sexual behavior of families need to instil religious and moral values to adolescents and schools can hold extracurricular activities that can increase the potential of adolescents. Therefore, the first sex education for adolescents should be done in a family environment by discussing it in accordance with the conditions of adolescents so that between children and parents there is openness. Parents also need to take the time to hear about the extent to which information has been understood by teenagers and how teenagers interpret about sexuality so that information received by teenagers is positive information. By knowing this, parents will know how to provide appropriate education to adolescents. So, teenagers' understanding of sexuality will be better and more positive.

There is a need for comprehensive assistance from families and schools during adolescence to access information, especially on sexuality, so that access to information obtained is positive information and can make regulations by prohibiting bringing mobile phones to schools to limit access to negative information. In addition, schools and governments can also work together to create a website / application / forum that can be a medium of information and discussion forum for adolescents related to sexuality. Because of sexual intercourse in adolescent may be linked to health related problems, such as, sexually transmitted infections (STIs), unwanted pregnancy, abortion and negative psychosocial health. It is pertinent to conceive strategies that may help to delay the first sexual intercourse

\section{Acknowledgement}

This study was supported by Universitas Esa Unggul from the internal research grant. The authors would like to express their deepest gratitude to students and teachers who participated in this study and the staff at Junior High School 2 Perbaung, North Sumatera.

\section{References}

Gaspar T, Gaspar M, Pais R, José L, Leal I, Ferreira A.(2009) Health-related quality of life in children and adolescents and associated psychosocial factors. J Cogn Behav Psychother. 2009 Mar; 9(1):33-48.

Furman, W., \& ShaVer, L. (2003). The Role of Romantic Relationships in Adolescent Development: Wyndol Furman and Laura Shaffer. In Adolescent romantic relations and sexual behavior (pp. 17-36). Psychology Press.

Kirby, D. B., Laris, B. A., \& Rolleri, L. A. (2007). Sex and HIV education programs: their impact on sexual behaviors of young people throughout the world. Journal of Adolescent Health, 40(3), 206-217. 
Selikow, T. A., Ahmed, N., Flisher, A. J., Mathews, C., \& Mukoma, W. (2009). I am not "umqwayito": A qualitative study of peer pressure and sexual risk behaviour among young adolescents in Cape Town, South Africa. Scandinavian Journal of Public Health, 37(2_suppl), 107-112.

Morojele, N. K., Brook, J. S., \& Kachieng'A, M. A. (2006). Perceptions of sexual risk behaviours and substance abuse among adolescents in South Africa: a qualitative investigation. AIDS care, 18(3), 215-219.

Bearinger, L. H., Sieving, R. E., Ferguson, J., \& Sharma, V. (2007). Global perspectives on the sexual and reproductive health of adolescents: patterns, prevention, and potential. The lancet, 369(9568), 1220-1231.

World Health Organization. (2015). Sexual and Reproductive Health.[Online]. Accessed in http://www.who.int/reproductivehealth/topics/adolescence/en/. accessed on 28th Agustus 2017.

World Health Organization (2017). Adolescents: health risks and solutions. [Online] accessed on http://www.who.int/mediacentre/factsheets/fs345/en/. 